\title{
Managing Public Debt, Money Supply and Foreign Assets: Some Indeterminacy Results*
}

\author{
Alexandre B. Cunha ${ }^{* *}$
}

Summary: 1. Introduction; 2. The economy; 3. Extension to optimal policies; 4. Conclusion.

Keywords: indeterminacy; monetary policy; exchange-rate regime.

JEL Codes: E52; E58; F31; H63.

We provide in this paper three indeterminacy results concerning competitive equilibrium in an open economy monetary model. First, we show that if Friedman's prescription of zero nominal interest rate is implemented, then the path of the nominal balances is not uniquely determined. Second, we show that the maturity of the public debt is undetermined in a competitive equilibrium. Finally, we show that any competitive equilibrium allocation and prices can be decentralized by distinct exchange-rate regimes.

Apresentam-se neste artigo três resultados de indeterminação do equilíbrio competitivo em um modelo do tipo pequena economia aberta com moeda. Inicialmente, mostra-se que se a famosa prescrição de Friedman de taxa nominal de juros zero for implementada, então a trajetória do estoque nominal de moeda é indeterminada. Em seguida, demonstra-se que a maturidade da dívida pública é indeterminada em um equilíbrio competitivo. Finalmente, mostrase que qualquer alocação e preços de equilíbrio competitivo podem ser descentralizados por distintos regimes cambiais.

\section{Introduction}

Keynes (1936) advocated the use of macroeconomic policies as a tool to affect such real variables as consumption, GDP and unemployment. Since then, the implications of alternative macroeconomic policies have been at center stage of the economic debate. For instance, in his presidential address to the American Economic Association, Lucas (2003) discussed the choice of main goals for US macroeconomic policy.

${ }^{*}$ This paper was received in Oct. 2004 and approved in Mar. 2005. The author acknowledges financial support from the Brazilian Council of Science and Technology (CNPq). An anonymous referee provided helpful comments. The usual disclaimer applies.

${ }^{* *}$ Faculdades Ibmec/RJ. E-mail: abcunha@ibmecrj.br. 
If we want to use macroeconomic policies to achieve specific goals, we must be able to understand the properties and implications of the policies we are pursuing. This essay has the modest aim of contributing to the understanding of implications of alternative paths for the money supply, maturity of the domestic public debt and exchange-rate regimes for the equilibrium realization of some macroeconomic variables such as consumption, output and devaluation.

We adopt a standard monetary small open economy model with a single infinitely lived household in this paper. We introduce money by means of a shoppingtime constraint. There is distorting taxation on labor income and free mobility of financial capital. Prices are fully flexible. As usual, government consumption is exogenous.

We provide three results in this paper. First, as Cole and Kocherlakota (1998) and Ireland (2003) have previously done, we show that if the Friedman rule of zero nominal interest rate is implemented, then the path of the nominal balances is not uniquely determined in a competitive equilibrium. Second, as in Lucas and Stokey (1983), we show that a competitive equilibrium pins down only the present value of the public debt and not its maturity. Third, we show that any competitive equilibrium is consistent with a floating exchange-rate regime and a non-floating one. As far as we know, this last result is original.

The reader will be able to verify that all results presented in this paper rely on the indifference of the household in allocating its wealth between domestic and foreign bonds and, when the nominal interest rate is zero, between bonds and money. Therefore, we conjecture that the results would hold in other types of economies. Our findings should survive even if we had introduced price stickiness or uncertainty in the model.

We can obtain an alternative interpretation to our results by relating them to the classic theorem of corporate finance of Modigliani and Miller (1958). They show there are several equivalent ways a firm can finance its investment projects. We show there are several equivalent manners a government can finance a stream of expenditures.

The results we present here are important for the same reason that the Modigliani-Miller theorem is relevant. Namely, we do not think that our results can be directly applied in the policy making arena. However, they provide a guidance on deciding which real world features have to be introduced in economic models to make government financing decisions matter.

Other authors have reached some similar indeterminacy results. Barro (1974) showed that if the government has access to lump-sum taxation, changes in government debt may have no real effects. Later, Kareken and Wallace (1981) showed 
that if two currencies are perfect substitutes, then the exchange rate between the two is undetermined in a competitive equilibrium. More recently, Basseto and Kocherlakota (2004) showed that if a government can levy distorting taxes on previously earned income, then Barro's aforementioned finding may hold even if the government does not have access to lump-sum taxation.

This paper is organized as follows. In section 2 we describe the model economy. In section 3 we define competitive equilibrium and establish our equivalence results. In section 4 we elaborate on possible generalizations of our results to contexts in which the government selects policies in an optimal fashion. We make concluding considerations in section 5 and present household's first-order conditions and all the proofs in the appendix.

\section{The Economy}

Consider a small country populated by a single infinitely lived household and a government. The household is endowed with one unit of time.

The country produces a unique good. This good is consumed by household $\left(c_{t}\right)$ and government $\left(g_{t}\right)$. It can also be exported $\left(x_{t}\right)$ or imported $\left(-x_{t}\right)$. As usual, the subscript $t$ denotes time.

A domestic currency $M_{t}$ circulates in this economy. Two types of securities are traded. The first type is a claim, with maturity of one period, on one unit of a foreign currency (for instance, the US dollar). The government and residents can purchase and/or sell this type of claim at a price, in terms of the foreign currency, $q_{t}^{*} ; B_{H t+1}^{*}$ and $B_{G t+1}^{*}$ denote, respectively, the number of these claims that household and government hold at end of period $t$. The second type is a claim, with all maturities, to one unit of the home currency. Foreigners do not buy or sell this type of claim. A claim that matures at some date $k>t$ is traded at date $t$ at a price, in terms of the home currency, $q_{t, k}$; the particular price $q_{t, t}$ is defined to be equal to one. The number of claims that mature at period $k$ outstanding at the end of period $t$ is denoted by $B_{t, k}$. If this last variable is positive the government has a debt to redeem at date $k$; if it is negative, then the government is a net creditor.

The household cannot sell its labor services outside the country. Technology is described by $0 \leq y_{t} \leq n_{t}$, where $y_{t}$ is the output of the unique good and $n_{t}$ is the amount of labor allocated to its production. The good is produced by a single competitive firm. Feasibility requires

$$
c_{t}+x_{t}+g_{t}=n_{t}
$$


The government finances the sequence $\left\{g_{t}\right\}_{t=0}^{\infty}$ by issuing and withdrawing the domestic currency; by issuing and redeeming claims on domestic currency; by purchasing and selling foreign assets; and by taxing labor income at a proportional $\operatorname{tax} \tau$. The sequence $\left\{g_{t}, \tau_{t}, q_{t}^{*}\right\}_{t=0}^{\infty}$ is exogenous.

The government budget constraint is

$$
\begin{gathered}
E_{t} g_{t}+E_{t} q_{t}^{*} B_{G t+1}^{*}+M_{t}+\sum_{k=t}^{\infty} q_{t, k} B_{t-1, k}= \\
\tau_{t} w_{t} n_{t}+E_{t} B_{G t}^{*}+M_{t+1}+\sum_{k=t+1}^{\infty} q_{t, k} B_{t, k},
\end{gathered}
$$

where

$w_{t}$ is the respective date $t$ monetary price (in terms of the domestic currency) of labor services; and $E_{t}$ is the nominal exchange rate. A negative value for $B_{G t+1}^{*}$ means that the government is borrowing abroad, while a negative value for $B_{t+1}$ means that the government is lending to domestic residents. At $t=0$ the government holds an initial amount $B_{G 0}^{*}$ of foreign assets and has an initial nominal debt $\left\{B_{-1, k}\right\}_{k=0}^{\infty}$. To avoid Ponzi schemes, standard boundedness constraints are imposed on government foreign assets and real public debt.

Purchases of the consumption good require the household's time. ${ }^{1}$ Money can reduce the amount of time the household devotes to purchasing activities. The amount of time $s_{t}$ used to purchase $c_{t}$ when the household's real balances are $\frac{M_{t}}{E_{t}}$ has to satisfy

$$
s_{t} \geq l\left(c_{t}, \frac{M_{t}}{E_{t}}\right) .
$$

The function $l$ is continuously differentiable and its partial derivatives respect $l_{1} \geq 0$ and $l_{2} \leq 0$.

The function $u: \mathbb{R}_{+} \times[0,1] \rightarrow \mathbb{R} \cup\{-\infty\}, u=u(c, 1-n-s)$ is the household period utility function. This function displays the usual monotonicity and quasiconcavity properties and satisfies standard differentiability and Inada conditions. Intertemporal preferences are described by

\footnotetext{
${ }^{1}$ For the purposes of this paper, it does not matter whether money is introduced in the economy by means of a cash-in-advance constraint or any other friction. Some of the results we present in this paper were obtained by other authors in cash-in-advance models. So, a minor advantage of our specification consists in extending the results in question to a distinct type of model.
} 


$$
\sum_{t=0}^{\infty} \beta^{t} u\left(c_{t}, 1-n_{t}-s_{t}\right),
$$

where $\beta \in(0,1)$. The date $t$ budget constraint of the household is

$$
\begin{aligned}
& E_{t} c_{t}+M_{t+1}+\sum_{k=t+1}^{\infty} q_{t, k} B_{t, k}+E_{t} q_{t}^{*} B_{H t+1}^{*} \leq \\
& \left(1-\tau_{t}\right) w_{t} n_{t}+M_{t}+\sum_{k=t}^{\infty} q_{t, k} B_{t-1, k}+E_{t} B_{H t}^{*}
\end{aligned}
$$

where $B_{H t+1}^{*}$ stands for the foreign assets held by the household at the end of date $t$. Standard boundedness constraints on foreign assets and real public debt prevent Ponzi schemes.

At date zero, given initial asset holdings $M_{0}, B_{H 0}^{*}$ and $\left\{B_{-1, k}\right\}_{k=0}^{\infty}$, the household chooses $\left\{c_{t}, n_{t}, s_{t}\right\}_{t=0}^{\infty},\left\{M_{t+1}, B_{H t+1}^{*}\right\}_{t=0}^{\infty}$ and $\left\{\left\{B_{t, k}\right\}_{k=t+1}^{\infty}\right\}_{t=0}^{\infty}$ to maximize (4) subject to the constraints (3), (5), and $n_{t}+s_{t} \leq 1$. Except for $B_{t, k}$ and $B_{H t+1}^{*}$, all these variables are constrained to be non-negative. Concerning the firm, at each period $t$ it chooses $n_{t}$ to maximize $E_{t} n_{t}-w_{t} n_{t}$.

\section{Competitive Equilibrium}

The definition of competitive equilibrium for this economy is standard. However, it is convenient to set up some notation. The array $\left(E_{t}, w_{t},\left\{q_{t, k}\right\}_{k=t+1}^{\infty}\right)$ is denoted by $\psi_{t}$, while $\psi$ stands for the sequence $\left\{\psi_{t}\right\}_{t=0}^{\infty}$. A date $t$ allocation $\left(x_{t}, c_{t}, n_{t}, s_{t}\right)$ is denoted by $\chi_{t}$, while $\varphi_{t+1}$ stands for end of period $t$ asset holdings $\left(M_{t+1},\left\{B_{t, k}\right\}_{k=t+1}^{\infty}, B_{H t+1}^{*}, B_{G t+1}^{*}\right)$. Additionally, $\chi=\left\{\chi_{t}\right\}_{t=0}^{\infty}$ and $\varphi=\left\{\varphi_{t+1}\right\}_{t=0}^{\infty}$.

Definition 1 A competitive equilibrium is an object $(\psi, \chi, \varphi)$ that satisfies: (i) given $\psi$ and $\left\{\tau_{t}, q_{t}^{*}\right\}_{t=0}^{\infty},(\chi, \varphi)$ provides a solution to the household problem; (ii) $w_{t}=E_{t}$; (iii) (1) and (2) hold.

A balance-of-payment condition was not spelled out in definition 1. It is not necessary to do so. Observe that adding the identity $w_{t} n_{t}=E_{t}\left(c_{t}+g_{t}+x_{t}\right)$ to (2) and (5) taken as equality, one obtains

$$
x_{t}+B_{G t}^{*}+B_{H t}^{*}-q_{t}^{*} B_{G t+1}^{*}-q_{t}^{*} B_{H t+1}^{*}=0,
$$

which is the balance-of-payments identity of this model economy. 
There is a condition on the term structure of the prices of domestic bonds that is required to prevent arbitrage opportunities. The equality

$$
q_{t, k+j}=q_{t, k} q_{k, k+j}
$$

ensures that people are indifferent between using, at date $t, q_{t, k+j}$ units of the domestic currency to buy one unit of the domestic currency to be delivered at date $k+j$ or using those resources to buy some amount of the domestic currency to be delivered at date $k$ and then using the proceeds of this last operation to buy deliveries of the domestic currency at date $k+j$.

As usual in open economy models, a competitive equilibrium must satisfy a condition that rules out arbitrage between domestic and foreign assets. An agent that at date $t$ has $q_{t}^{*}$ dollars must be indifferent between buying a dollar to be delivered at $t+1$ or converting these $q_{t}^{*}$ dollars into domestic currency, using the proceeds to buy one-period claims on the domestic currency and converting the proceeds of this last operation back into dollars. Thus, nominal exchange rate and domestic and foreign bond prices must satisfy

$$
q_{t}^{*}=\frac{E_{t+1}}{E_{t}} q_{t, t+1}
$$

The next proposition formalizes the above discussion.

Proposition 1 If $(\psi, \chi, \varphi)$ is a competitive equilibrium, then it satisfies $(7)$ and (8).

Proof. See appendix.

\subsection{The Friedman rule}

In a seminal essay, Friedman (1969) suggested that a government should set the nominal interest rate equal to zero to lead the economy to an efficient outcome. He argued that only such a policy would achieve maximization of the consumer surplus associated with money demand. That policy prescription became known in the literature as the Friedman rule.

Friedman's argument was a partial equilibrium one. Lucas and Stokey (1983) were the first to show that the optimality of the Friedman rule could also hold in a general equilibrium context, provided that the government had access to lumpsum revenues. Later, Kimbrough (1986) showed that the Friedman rule could be 
optimal even if all revenue sources were distorting ones. After Lucas and Stokey's and Kimbrough's papers, a large body of literature addressed the optimality of the Friedman rule when all tax revenue sources are distorting. Chari and Kehoe (1999) provide a survey on the optimality of the Friedman rule.

In our economy, the Friedman rule amounts to

$$
q_{t, k}=1
$$

for all $t$ and $k$. As pointed out by Cole and Kocherlakota (1998) and Ireland (2003), (9) implies that the money supply has to satisfy the following long-run property:

$$
\lim _{t \rightarrow \infty} M_{t}=0
$$

We formalize this fact in the next proposition.

Proposition 2 If a competitive equilibrium $(\psi, \chi, \varphi)$ satisfies $(9)$, then it satisfies (10).

Proof. See appendix.

Cole and Kocherlakota (1998) and Ireland (2003) argue that the implementation of the Friedman rule leaves the path of nominal balances undetermined. The next proposition establishes that the same holds in the economy we consider in this paper.

Proposition 3 If a competitive equilibrium $(\psi, \chi, \varphi)$ satisfies $(9)$, then there are uncountably many $\hat{\varphi}$ such that $(\psi, \chi, \hat{\varphi})$ is a competitive equilibrium.

Proof. See appendix.

The intuition for the aforementioned indeterminacy is extremely simple. If the nominal interest rate is zero, people will be indifferent between domestic bonds and money, provided they have enough balances to purchase the desired amount of the consumption good. Thus, the government can carry out open market operations that increase the amount of nominal balances and decrease the domestic public debt by the same amount without affecting prices and allocations. One can easily relate this situation to the well-known liquidity trap. 
In Cole and Kocherlakota (1998) and Ireland (2003), the government has access to lump-sum taxation and inflation is the only distorting tax available. Therefore, the Friedman rule (9) is a necessary and sufficient condition for Pareto optimality. Hence, in those papers the result presented in proposition 3 is exclusively associated with the unique Pareto efficient allocation. This is not the case here. The result in question is true regardless of the optimality of the policy rule (9).

Proposition 3 has two striking implications. First, there are several paths for the money supply that are consistent with implementation of the Friedman rule (9). Second, there are uncountably many paths for the money supply $\left\{M_{t+1}\right\}_{t=0}^{\infty}$ that will lead to a same price level path $\left\{E_{t}\right\}_{t=0}^{\infty}$. Thus, as Cole and Kocherlakota (1998) pointed out, exactly when the Friedman rule is implemented, the well-known statement that "inflation is always and everywhere a monetary phenomenon" found in Friedman (1963) cannot be applied.

\subsection{The maturity of the public debt}

Lucas and Stokey (1983) studied the properties of optimal macroeconomic policies in a dynamic stochastic general equilibrium setup. They showed that a competitive equilibrium would pin down, at each date $t$, the present value of the public debt in a unique way. However, its maturity structure was undetermined. The same result holds in the economy we consider in this paper.

Take any sequences of domestic bond prices $\left\{\left\{q_{t, k}\right\}_{k=t+1}^{\infty}\right\}_{t=0}^{\infty}$ and assets $\varphi$. Let $\hat{\varphi}$ be any alternative array of assets satisfying, for all $t$,

$$
\sum_{k=t+1}^{\infty} q_{t, k} B_{t, k}=\sum_{k=t+1}^{\infty} q_{t, k} \hat{B}_{t, k}
$$

and

$$
\hat{\varphi}_{t+1}=\left(M_{t+1},\left\{\hat{B}_{t, k}\right\}_{k=t+1}^{\infty}, B_{H t+1}^{*}, B_{G t+1}^{*}\right) .
$$

Note that (11) ensures $\varphi$ and $\hat{\varphi}$ specify the same present value of the domestic public debt at every date $t$. The following proposition establishes that the maturity of the public debt is irrelevant in a competitive equilibrium.

Proposition 4 If $(\psi, \chi, \varphi)$ is a competitive equilibrium and $\hat{\varphi}$ satisfies (11) and (12), then $(\psi, \chi, \hat{\varphi})$ is a competitive equilibrium. 
Proof. See appendix.

The above proposition implies that if a government can credibly commit to a given macroeconomic policy, the maturities of the bonds it will use while implementing the policy in question do not matter. The assumption that the government is able to keep its promise is essential here. In Section 4 we will briefly discuss the relevance of the debt maturity to the time consistency of macroeconomic policy.

\subsection{The exchange-rate regime}

The implications of adopting an exchange rate regime constitute an old debate in economics. Friedman (1953) strongly advocates the adoption of floating exchange rates. According to him, they are desirable from a welfare point of view. Fifty years later, economists still argue over the selection of an exchange rate regime. Calvo and Reinhart (2000, 2002), Obstfeld and Rogoff (1995) and Tornell and Velasco (2000) are relatively recent papers that discuss this issue.

Usually, the exchange rate is said to float if the government does not intervene in the foreign exchange market. This concept appears in textbooks (for instance, Rodseth (2000), page 11 and Stockman (1999), page 787) and research papers (such as Rigobon (2002), page 275). The next definition follows this tradition.

Definition 2 The exchange rate floats at date $t$ in a competitive equilibrium $(\psi, \chi, \varphi)$ if $B_{G t+1}^{*}=B_{G t}^{*}$.

At least since Krugman (1991), it has been known that if the government will intervene in the foreign exchange market sometime in the future, this will affect the price of the foreign currency today. Thus, it may be convenient to distinguish permanent from temporary floating.

Definition 3 The exchange rate permanently floats in a competitive equilibrium $(\psi, \chi, \varphi)$ if $B_{G t+1}^{*}=B_{G 0}^{*}$ for all $t$.

The last definition requires the government never to intervene in the foreign exchange market. This requirement is clearly stronger than the one stated in definition 2 . 
As we pointed out in proposition 1, absence of arbitrage between domestic and foreign bonds requires that the household must be indifferent in allocating its wealth between these two types of assets. The next two propositions rely on this fact.

Proposition 5 If $(\psi, \chi, \varphi)$ is a competitive equilibrium, then there exists a sequence $\hat{\varphi}$ such that $(\psi, \chi, \hat{\varphi})$ is a competitive equilibrium in which the exchange rate permanently floats.

Proof. See appendix.

Proposition 6 If $(\psi, \chi, \varphi)$ is a competitive equilibrium, then there exists a sequence $\hat{\varphi}$ such that $(\psi, \chi, \hat{\varphi})$ is a competitive equilibrium in which the exchange rate never floats.

Proof. See appendix.

The intuition behind propositions 5 and 6 is very simple. Arbitrage opportunities are ruled out in a competitive equilibrium. Therefore, people are indifferent between the two type of bonds. This allows the government to change the composition of its debt without affecting its value. For instance, the government can sell abroad $\Delta$ units of foreign currency denominated bonds. Simultaneously, people sell to the government $\frac{E_{t} q_{t}^{*} \Delta}{q_{t}}$ units of domestic debt and use the proceeds to buy exactly $\Delta$ units of foreign bonds. This type of financial operation does not change the wealth of the government, people or the external sector.

It should be emphasized that propositions 5 and 6 hold in other environments. They would hold even if capital mobility were not perfect and/or people and government faced different interest rates in the international market. They would also hold in different monetary economies, such as a money-in-the utility function one. ${ }^{2}$

Propositions 5 and 6 together established that any competitive equilibrium in which the exchange rate floats is equivalent (in the sense that allocations and prices are the same) to one in which the exchange rate does not float and viceversa. Hence, it is not a very fruitful exercise to discuss the advantages and disadvantages of floating and fixed exchange-rate regimes without modeling the government's behavior.

\footnotetext{
${ }^{2}$ Interestingly, it is possible to establish results equivalent to propositions 5 and 6 in stochastic economies. 
For the particular case of fixed-exchange-rate policies, the last two propositions have an interesting implication. Suppose that a government can credibly commit to an exchange rate level. A classical way of achieving this outcome is to create a currency board. However, proposition 5 implicates that the desired outcome can be achieved by means of a floating exchange-rate policy, while proposition 6 shows that daily interventions in the exchange market are another way of achieving the desired outcome.

\section{Extension to Optimal Policies}

The concept of competitive equilibrium does not impose optimal behavior on the government. Thus, a natural question is whether propositions 3-6 can be generalized to games in which the government is an active player. The answer depends on the type of game being considered.

If the government payoff depends on the asset array $\varphi$, none of the propositions will remain true. But there is no obvious reason for such a type of payoff to be a good starting point to model the government's behavior. Therefore, in the discussion that follows, we assume the government payoff depends only on $\psi$ and $\chi$. Note that the standard situations in which the government payoff is given by household lifetime utility (4) or by a loss function that depends on currency devaluation and on output gap are particular cases of the one we are considering here.

Assume that the government selects lifetime monetary and exchange-rate policies at date zero. Then, the government announces the policies it picked. Suppose that the announcement is fully credible. Then, markets open and private agents trade. Clearly, all results presented in propositions 3-6 remain true. Whenever the government can commit to a policy and it does not care about the assets $\varphi$ that emerge as an equilibrium result, it does not matter how the government will implement a particular competitive equilibrium.

Since a seminal paper by Calvo (1978), the time consistency of monetary policy has been the focus of several papers. The time consistency problem arises as a consequence of a government inability to commit to a previously selected policy.

Lucas and Stokey (1983) showed that the maturity structure of the public debt was important to make an optimal taxation policy time-consistent. In a recent work, Alvarez et al. (2004) concluded that the same result applies to the optimal monetary policy. Obstfeld (1994) reached the same conclusion when studying the determinants of exchange-rate devaluations. On the other hand, propositions 3-6 depend on the irrelevance of the composition of people's wealth and the govern- 
ment's debt and foreign assets. Therefore, the results we present in this essay do not necessarily generalize to situations in which the government cannot credibly commit to a macroeconomic policy. This leads us to conclude that to be able to make non-empty statements on the relevance of public debt maturity, optimal nominal quantity of money and benefits of exchange-rate regimes one must consider games in which the government is an active player and cannot commit to a macroeconomic policy.

\section{Conclusion}

In this paper we studied the implications of alternative policies for money supply, maturity of the domestic public debt and exchange-rate regime in a standard monetary small open economy model. We showed that if the Friedman rule (i.e., zero nominal interest rate) is implemented, then there are several distinct paths for the money supply and public debt that will lead to the same competitive equilibrium allocation and price path. We also showed that a competitive equilibrium only pins down the path of the discounted present value of the public debt and its maturity is irrelevant. Concerning the exchange rate regime, we showed that any competitive equilibrium allocation and price path are consistent with floating and non-floating exchange-rate regimes.

We obtained the aforementioned findings in a context in which policy makers are passive players. There is no feedback between their actions and expectations of private agents. Particularly, we abstained from time consistency issues. Therefore, to understand the relevance of public debt maturity, optimal nominal quantity of money and benefits of exchange-rate regimes we should study models of policy selection in which the government is not able to commit to a policy.

\section{References}

Alvarez, F., Kehoe, P. J., \& Neumeyer, P. A. (2004). The time consistency of optimal monetary and fiscal policies. Econometrica, 72(2):541-567.

Barro, R. J. (1974). Are government bonds net wealth? Journal of Political Economy, 82(6):1095-1117.

Basseto, M. \& Kocherlakota, N. (2004). On the irrelevance of government debt when taxes are distortionary. Journal of Monetary Economics, 51(2):399-436. 
Calvo, G. A. (1978). On the time consistency of optimal policy in a monetary economy. Econometrica, 46(6):1411-1428.

Calvo, G. A. \& Reinhart, C. M. (2000). Fixing for your life. National Bureau of Economic Research. Working Paper 8006.

Calvo, G. A. \& Reinhart, C. M. (2002). Fear of floating. Quarterly Journal of Economics, 117(2):379-408.

Chari, V. V. \& Kehoe, P. J. (1999). Optimal fiscal and monetary policy. In Taylor, J. B. \& Woodford, M., editors, Handbook of Macroeconomics Volume 1C. North-Holland, Amsterdam.

Cole, H. L. \& Kocherlakota, N. (1998). Zero nominal interest rates: Why they are good and how to get them. Federal Reserve Bank of Minneapolis Quarterly Review, 22(2):2-10.

Friedman, M. (1953). The case for flexible exchange rates. In Essays in Positive Economics. The University of Chicago Press, Chicago.

Friedman, M. (1963). Inflation: Causes and Consequences. Asia Publishing House, Bombay.

Friedman, M. (1969). The optimum quantity of money. In The Optimum Quantity of Money and Other Essays. Aldine Publishing Company, Chicago.

Ireland, P. N. (2003). Implementing the Friedman rule. Review of Economic Dynamics, 6(1):120-134.

Kareken, J. \& Wallace, N. (1981). On the indeterminacy of equilibrium exchange rates. Quarterly Journal of Economics, 96(2):207-222.

Keynes, J. M. (1936). The General Theory of Employment, Interest and Money. Harcourt \& Brace, New York.

Kimbrough, K. P. (1986). The optimum quantity of money in the theory of public finance. Journal of Monetary Economics, 18(3):277-284.

Krugman, P. R. (1991). Target zones and exchange rate dynamics. Quarterly Journal of Economics, 106(3):669-682.

Lucas, Jr., R. E. (2003). Macroeconomic priorities. American Economic Review, $93(1): 1-14$. 
Lucas, Jr., R. E. \& Stokey, N. L. (1983). Optimal fiscal and monetary policy in an economy without capital. Journal of Monetary Economics, 12(1):55-93.

Modigliani, F. \& Miller, M. H. (1958). The cost of capital, corporation finance and the theory of investment. American Economic Review, 58(3):261-297.

Obstfeld, M. (1994). The logic of currency crises. Cahiers Économiques et Monétaires de la Banque de France, 43:189-213.

Obstfeld, M. \& Rogoff, K. (1995). The mirage of fixed exchange rates. Journal of Economic Perspectives, 9(4):73-96.

Rigobon, R. (2002). Disinflation and fiscal reform: A neoclassical perspective. Journal of International Economics, 58(2):265-297.

Rodseth, A. (2000). Open Economy Macroeconomics. Cambridge University Press, Cambridge.

Stockman, A. C. (1999). Introduction to Economics. The Dryden Press, second edition.

Tornell, A. \& Velasco, A. (2000). Fixed versus flexible exchange rates: Which provides more fiscal discipline? Journal of Monetary Economics, 45(2):399436. 


\section{Appendix}

\section{A.1 Household's first-order conditions}

If $M_{0}$ is positive, the first-order necessary conditions for the household are

$$
\begin{gathered}
\beta^{t} u_{1}\left(c_{t}, 1-n_{t}-s_{t}\right)=\lambda_{t} E_{t}+\mu_{t} l_{1}\left(c_{t}, \frac{M_{t}}{E_{t}}\right) \\
\beta^{t} u_{2}\left(c_{t}, 1-n_{t}-s_{t}\right)=\lambda_{t}\left(1-\tau_{t}\right) w_{t} \\
\beta^{t} u_{2}\left(c_{t}, 1-n_{t}-s_{t}\right) \geq \mu_{t} \& s_{t}\left[\beta^{t} u_{2}\left(c_{t}, 1-n_{t}-s_{t}\right)-\mu_{t}\right]=0 \\
\lambda_{t}=\lambda_{t+1}+\frac{l_{2}\left(c_{t+1}, \frac{M_{t+1}}{E_{t+1}}\right)}{E_{t+1}} \mu_{t+1}=\lambda_{t+1} q_{t+1, k} \\
\lambda_{t} E_{t} q_{t}^{*}=\lambda_{t+1} E_{t+1} \\
s_{t} \geq l\left(c_{t}, \frac{M_{t}}{E_{t}}\right) \& \mu_{t}\left[s_{t}-l\left(c_{t}, \frac{M_{t}}{E_{t}}\right)\right]=0 \\
\lim _{t \rightarrow \infty} c_{t}+M_{t+1}+\sum_{k=t+1}^{\infty} q_{t, k} B_{t, k}+E_{t} q_{t}^{*} B_{H t+1}^{*}= \\
\left(1-\tau_{t}\right) w_{t} n_{t}+M_{t}+\sum_{k=t}^{\infty} q_{t, k} B_{t-1, k}+E_{t} B_{H t}^{*} \\
\left.\sum_{k=t+1}^{\infty} q_{t, k} B_{t, k}+E_{t} q_{t}^{*} B_{H t+1}^{*}\right)=0
\end{gathered}
$$

where $\lambda_{t}$ and $\mu_{t}$ are Lagrange multipliers for, respectively, budget and transaction technology constraints. 


\section{A.2 Proofs}

Proof of Proposition 1: This proof is standard. Let us start with (8). We will show that if a sequence of prices $\psi$ specifies $E_{t} q_{t}^{*} \neq E_{t+1} q_{t}$ at some date $t$, there is no pair $(\chi, \varphi)$ such that $(\psi, \chi, \varphi)$ is a competitive equilibrium. Assume that $E_{t} q_{t}^{*}<E_{t+1} q_{t}$ and let $(\chi, \varphi)$ be any affordable pair of allocations and assets. Consider the following trading strategy for the household: At date $t$ sell $\varepsilon>0$ units of the domestic asset and purchase $\frac{q_{t}}{E_{t} q_{t}^{*}} \varepsilon$ units of the foreign asset. Clearly, such strategy respects the date $t$ budget constraint (5). At date $t+1$ the consumer will have to pay back additional $\varepsilon$ due to her higher domestic liabilities and receive an additional $\frac{E_{t+1} q_{t}}{E_{t} q_{t}^{*}} \varepsilon$ units from her higher foreign assets. But

$$
E_{t} q_{t}^{*}<E_{t+1} q_{t} \Rightarrow \frac{E_{t+1} q_{t}}{E_{t} q_{t}^{*}} \varepsilon>\varepsilon
$$

Therefore, the proposed trading strategy leads to a lessening of the date $t+1$ budget constraint and allows the consumer to have higher utility than that $\chi$ specifies. Hence, $(\psi, \chi, \varphi)$ cannot be a competitive equilibrium. The opposite trading strategy establishes the desired result if $E_{t} q_{t}^{*}>E_{t+1} q_{t}$. Similar reasoning establishes (7).

Proof of Proposition 2: Let $(\psi, \chi, \varphi)$ be a competitive equilibrium that satisfies (9). This equation and (A.5) imply $\lambda_{t}=\lambda_{t+1}$. So, (A.9) implies (10).

Proof of Proposition 3: Let $(\psi, \chi, \varphi)$ be a competitive equilibrium that satisfies (9). Let $\left\{\hat{M}_{t+1}\right\}_{t=0}^{\infty}$ be any sequence satisfying $\hat{M}_{t+1} \geq M_{t+1}$ and (10). Define $\hat{B}_{t, t+1}=M_{t+1}+B_{t, t+1}-\hat{M}_{t+1}, \hat{B}_{t, k}=B_{t, k}$ for $k \geq t+2$ and $\hat{\varphi}_{t+1}=$ $\left(\hat{M}_{t+1},\left\{\hat{B}_{t, k}\right\}_{k=t+1}^{\infty}, B_{H t+1}^{*}, B_{G t+1}^{*}\right)$. Note that $\hat{\varphi}_{t+1}$ will necessarily satisfy people's and government's budget constraints. It remains to show that $(\varphi, \chi, \hat{\varphi})$ is a competitive equilibrium. It trivially satisfies conditions (ii) and (iii) of definition 1. To show that condition (i) is satisfied, we will prove that had it failed, then $(\psi, \chi, \varphi)$ would not be a competitive equilibrium. Assume that condition (i) of definition 1 were not satisfied. So, there would exist an affordable sequence $\left\{\hat{c}_{t}, \hat{n}_{t}, \hat{s}_{t}, \hat{M}_{t+1},\left\{\hat{B}_{t, k}\right\}_{k=t+1}^{\infty}, \hat{B}_{H t+1}^{*}\right\}_{t=0}^{\infty}$ satisfying $\sum_{t=0}^{\infty} \beta^{t} u\left(\hat{c}_{t}, 1-\hat{n}_{t}-\hat{s}_{t}\right)>\sum_{t=0}^{\infty} \beta u\left(c_{t}, 1-n_{t}-s_{t}\right)$. But this would imply that $\left\{c_{t}, n_{t}, s_{t}, M_{t+1},\left\{B_{t, k}\right\}_{k=t+1}^{\infty}, B_{H t+1}^{*}\right\}_{t=0}^{\infty}$ were not an optimal choice for the household when the prevailing prices were $\psi$. Hence, $(\psi, \chi, \varphi)$ could not be a competitive equilibrium. 
Proof of Proposition 4: Let $(\psi, \chi, \varphi)$ be a competitive equilibrium and $\hat{\varphi}$ a sequence that satisfies (11) and (12). Combine this former equality with (A.5). Hence,

$$
\begin{aligned}
\sum_{k=t+1}^{\infty} \lambda_{t} q_{t, k} B_{t, k} & =\sum_{k=t+1}^{\infty} \lambda_{t} q_{t, k} \hat{B}_{t, k} \Rightarrow \\
\sum_{k=t+1}^{\infty} \lambda_{t+1} q_{t+1, k} B_{t, k} & =\sum_{k=t+1}^{\infty} \lambda_{t+1} q_{t+1, k} \hat{B}_{t, k} \Rightarrow \\
\sum_{k=t+1}^{\infty} q_{t+1, k} B_{t, k} & =\sum_{k=t+1}^{\infty} q_{t+1, k} \hat{B}_{t, k}
\end{aligned}
$$

Condition (11) and the last equality in (A.10) imply that $(\psi, \chi, \hat{\varphi})$ respects the budget constraints of government and household. Finally, the reasoning we used at the end of proposition 3 establishes that $(\psi, \chi, \hat{\varphi})$ is a competitive equilibrium.

Proof of Proposition 5: The first step is to construct the sequence $\hat{\varphi}$. For each $t$, set $\hat{M}_{t+1}=M_{t+1}$ and $\hat{B}_{G t+1}^{*}=B_{G 0}^{*}$. Of course, the initial public debt is still $\left\{B_{-1, k}\right\}_{k=0}^{\infty}$. Hence, it is possible to define $\left\{\left\{\hat{B}_{t, k}\right\}_{k=t+1}^{\infty}\right\}_{t=0}^{\infty}$ recursively according to $\hat{B}_{t, k}=B_{t, k}$ for all $t$ and all $k \geq t+2$ and

$$
\begin{gathered}
q_{t, t+1} \hat{B}_{t, t+1}=E_{t} g_{t}+E_{t} q_{t}^{*} B_{G 0}^{*}+M_{t}+ \\
\sum_{k=t}^{\infty} q_{t, k} \hat{B}_{t-1, k}-\tau_{t} w_{t} n_{t}-E_{t} B_{G 0}^{*}-M_{t+1} .
\end{gathered}
$$

Similarly, use the equation

$$
\begin{gathered}
E_{t} q_{t}^{*} \hat{B}_{H t+1}^{*}=\left(1-\tau_{t}\right) w_{t} n_{t}+M_{t}+ \\
\sum_{k=t}^{\infty} q_{t, k} \hat{B}_{t-1, k}+E_{t} \hat{B}_{H t}^{*}-E_{t} c_{t}-M_{t+1}-\sum_{k=t+1}^{\infty} q_{t, k} \hat{B}_{t, k}
\end{gathered}
$$

to construct $\left\{\hat{B}_{H t+1}^{*}\right\}_{t=0}^{\infty}$ in a recursive manner. 
Observe that $\hat{\varphi}$ was constructed in such a way that both government and people respect their respective budget constraints and the exchange rate permanently floats. Again, the reasoning we used at the end of proposition 3 establishes that $(\psi, \chi, \hat{\varphi})$ is a competitive equilibrium.

Proof of Proposition 6: Let $\delta$ be any real number other than zero. For each $t$, set $\hat{B}_{G t+1}^{*}=B_{G 0}^{*}+(-1)^{t+1} \delta$. Define $\left\{\hat{M}_{t+1},\left\{\hat{B}_{t, k}\right\}_{k=t+1}^{\infty}, \hat{B}_{H t+1}^{*}\right\}_{t=0}^{\infty}$ as in the last proof. As in the previous proposition, $(\psi, \chi, \hat{\varphi})$ is a competitive equilibrium. Since $\hat{B}_{G t+1}^{*}-\hat{B}_{G t}^{*} \neq 0$ for each $t$, the exchange rate never floats in this competitive equilibrium. 